2016 Global Marketing Conference at Hong Kong Proceedings: 597-601 (July 2016) http://dx.doi.org/10.15444/GMC2016.05.03.05

\title{
WHAT CAN WE KNOW FROM SELFIES- AN EXPLORATORY STUDY ON SELFIE AND THE IMPLICATION FOR MARKETERS
}

\author{
Jenny Weichen Ma, University of Greenwich, $\mathrm{UK}^{1)}$ \\ Yusheng Yang, University of Worcester, $\mathrm{UK}^{2)}$
}

\begin{abstract}
Although "selfie" has become a social phenomenon, little is discussed in marketing literature regarding what marketers can actually learn from consumers using selfies. This study has collected cross-cultural data of a total of 396 selfie photos from Twitter and Sina Weibo, in order to provide empirical evidence that leads to a better understanding on selfies. The results emphasise the cross-cultural differences on taking selfies and how selfie as another form of consumers presenting the "ideal self" may influence what information marketers can obtain from consumer selfies. The limitations due to data collection methods are noted and implications for marketers are also discussed.
\end{abstract}

Keywords: selfies, cultural differences, consumer studies, social media

\section{INTRODUCTION}

"Selfie", the word of 2013 according to Oxford Dictionary, refers to "a self- portrait photography of oneself (or oneself with other people), taken with a camera or a camera phone held at arm's length or pointed at a mirror, which is usually shared through social media" (Sorokowski et al., 2015). Marketers have discussed the potential benefits of monitoring consumers' selfies for marketing use. According to Wall Street Journal (2014), companies have already developed software for scanning individual selfie as part of the big data marketing, as they expected to find consumer emotion, product usage, and lifestyle from an individual's selfie. However, there is still lack of empirical evidence on what information marketers can gain from monitoring consumer selfies. Furthermore, while "selfie" remains as a trendy topic for marketers and consumer researchers, the way in which selfies can contribute to marketing is still a myth for many. This study aims to provide empirical evidence on consumer selfies from China and the UK to answer the question "what can we know from a consumer selfie". The contribution of this study is not only its exploratory nature but also the cross-cultural evidence of selfies for marketers and consumer researchers.

\section{THEORETICAL BACKGROUND}

As a relatively new social phenomenon, the literature regarding selfie is limited, especially in the field of marketing. Selfie, as it is mostly shared on social networking sites (SNS), it can be explained by the two basic social needs that drive people to use

1)j.ma@worc.ac.uk

2) yany1_15@uni.worc.ac.uk 


\section{Global Marketing Conference at Hong Kong}

SNS- need to belong and the need to self-presentation (Nadkarni \& Hofmann, 2012). The motivation to take a selfie and the drive of social needs have led researchers focus on the topic of individual differences regarding selfies, especially individual personality traits. For instance, selfie posting behaviour has been linked to extraversion and narcissism personality traits (Weiser, 2015; Sorokowska, Oleszkiewicz, Frackowiak, \& Pisanski, 2016), and individuals' specific ways of doing a selfie (e.g. duckface) has also been found as an indicator for personality types (Qiu, Lu, Yang, Qu, \& Zhu 2015). Qui et al. (2015) finalized their selfie coding scheme and found that except facial expression such as duckface or pressed lips, individual emotions, location information, and whether the picture is edited with Photoshop can be accounted as codes for selfie analysis. They also found that these cues are personality-related- for instance, duckface was linked to neuroticism, and private location could suggest less conscientiousness. Such studies have certainly provided us an insight on what information could be obtain from a selfie.

However, little implication was provided to marketers by the existing literature, as the current selfie literature has not yet been comprehensively discussed with marketing literature. What we currently know or assume about selfie (e.g. individual show-off; only young people do it etc.) may not be correct. Or at least, our assumption regarding selfies will need some empirical and systematic data to support them, before marketers can actually take selfie into consideration for their marketing planning. Practitioners argued "a selfie that has a "look at me" message is very different to selfie that is "look at me here or with this item of significance to me" - brands need to understand the difference." (The Guardian, 2015). Another knowledge gap is the cultural differences. There is a large amount of literature which suggests that self-presentation will vary in different cultural context. For example, Kim and Papacharissi (2003) investigated whether there is a cultural difference in how people present their personal webpage and found that while the US samples presented themselves in a direct and personal manner, the Korean counterparts resented the online self by providing interlinks to special interests and were more likely to use manipulated graphics. Since selfie is now a common form of selfpresentation, individual's cultural background may influence the way in which their selfies are presented. Therefore, this study aims to enhance our understanding on selfie by collecting cross-cultural data and hopes to provide marketing implication.

\section{METHOD}

The data is collected on Twitter and Sina Weibo (Chinese most popular microblogging website similar to Twitter). The researchers collected totally 420 selfies from both Twitter and Sina Weibo users (210 selfies each). After excluding 74 photos which cannot be determined as selfie or not, the total sample was 346, consisting 269 females and 77 are males. (210 of Weibo and 136 of Twitter).

To collect the public data, the researcher used 'selfie' (or “自拍”, selfie in Chinese) as the search term and downloaded the link for first 20 selfies shown in both Twitter and Sina Weibo from 20:00 to 22:00 in UK and China time separately. The data collection procedure lasted for seven days. To code the selfies, we selected picture coding cues that are appropriate for coding selfies from past research (Qiu et al. 2015). The cues include 


\section{Global Marketing Conference at Hong Kong}

selfie taken location ( $1=$ private place such as bedroom, toilet, student accommodation; $2=$ public place such as hotel, workplace, shopping mall, campus), eye looking at the camera $(1=$ looking at the camera, $2=$ not looking at the camera), Photoshop editing $(1=$ Photoshop edited, 2=no Photoshop edited), affiliation with friends $(1=$ alone, $2=$ affiliation with friends), collage photos $(1=$ collage photos, $2=$ not collage photos $)$, physical appearance ( 1 =face, $2=$ body from breast, $3=$ half body, $4=$ whole body), position in photo $(1=$ central in photo, $2=$ left in photo, $3=$ right in photo $)$, makeup $(1=$ makeup, $2=$ no makeup), emotion (1=positive emotion, $2=$ negative emotion, $3=$ no emotion). Besides these, based on gesture and facial expression, the photos were classified into 'yeah gesture', 'duck face', 'selfie via mirror', 'pout mouth', 'hand position'. The objects in the selfies, if any, were also noted by the researchers. In summary, content analysis and thematic analysis are both used to complete the data analysis. Crosstab Chi-square test was used to compare the data cross-culturally.

\section{RESULT AND ANALYSIS}

First of all, the study reveals that there is a significant culture difference on the way in which individuals was presented in their selfies $(\mathrm{p}<0.01)$. For Chinese, more than $80 \%$ of the selfies showed the face or the above chest of the photo takers, while almost $40 \%$ of the selfies from Twitter showed the half or the whole body of the photo takers. This result may explain the findings regarding location. While there is no significance difference between two cultures, the results indicated that $41.9 \%$ of the Chinese selfies did not reveal any location information. This implies that it is less efficient for marketers to obtain location information from Chinese consumers. Some of the Chinese selfies suggested that some photo takers particularly hide the location information by using Photoshop to blur the background. Photo editing is another significant culture difference found in this study $(\mathrm{p}<0.01) .77 .6 \%$ of the Chinese selfies collected have obvious use for Photoshop, especially on individuals' appearance, whilst only $35.8 \%$ of the Twitter selfies were found to be edited. This implies that selfie for Chinese users is not merely a self-presentation but a presentation for their "ideal selves".

This finding corresponds to several marketing research on Chinese consumers. For examples, Sun and Wu (2004) argued that Chinese consumers use different products to reflect their ideal selves and to show the improvement of their life standard. Zhao and Belk (2007) also stated that the fact that young Chinese consumers actively posting their consumption activities on their blogs (e.g. malls visit, restaurants etc.) is linked to the concept of "extended self" and acquiring material items. The internet provides a new means or self-extension through posting images of the ideal self (Zhao \& Belk, 2007), in this case, selfies. This can also explain why more percentage of Chinese selfies was found to have makeup $(44.9 \%, \mathrm{p}<0.05)$. This finding could also imply that previous researchers argue selfie-posting behaviour and its correlation to narcissism may not apply in the Chinese context. Rather, Chinese selfie-posting can be seen as an act to boost selfesteem. This could explain why previous studies on selfie-posting behaviour and narcissism often generate inconclusive results (Sorokowska et al., 2016). 


\section{Global Marketing Conference at Hong Kong}

Similar to the concept of the "ideal-self", for the selfies on Twitter, some selfies were found to be taken in bathrooms (e.g. finished makeup before going out) whilst none has been found in the Chinese samples. Other common private location for both cultures include bedroom (34.8\% of Chinese and $17.3 \%$ of Twitter users) and inside the car $(7.2 \%$ of Chinese and $15.4 \%$ of Twitter users). This suggests that selfie behaviour may be linked to consumer grooming ritual. Rook (1985) argued that consumer grooming patterns and use of consumer items and brands can be seen as a consumer ritual which consumers adopt in order to work on a more ideal self. Moreover, twitter selfies were also found to imply more sex appeals in this study, especially when selfies were taken with half or the whole body of the photo takers (e.g. breasts, bottoms, and chest/belly muscle). A crosscultural study on sex image used in advertising revealed that Chinese consumer had the least positive attitudes when it comes to sex images used in advertising in comparison to the counterparts from USA and Canada (Liu, Cheng, \& Li, 2009). Along with the results of this study, it may imply that the image of being "sexy" is less valued by Chinese, and this attitude can be reflected on their selfies.

\section{CONCLUSION}

This study has provided several interesting insights regarding selfies which can provide practical implication for marketers. Firstly, Chinese selfies are heavily linked to photo editing tools such as Photoshop. Chinese smartphone brand, Huawei, actually promoted their smartphone by emphasizing that photo editing apps are pre-installed to their phones. The concept of presenting the "ideal self" can also correspond to Chinese behaviour such as overspending and luxury consumption (Zhao \& Belk, 2007). More importantly, this study provides an indication for marketers and future researchers- selfie, as an selfpresenting behaviour, should be investigated with the consideration of cultural context. For instance, marketer may not be able to acquire much information regarding selfie location in China.

Although this study provides a better understanding of selfie behaviour, it has several limitations. Firstly, due to the data collection method, individual background information such as age and socio economic status was excluded, although it might have an impact on selfie behaviour. Also, the selfies were collected in two hours in each seven days, this could lead to the issues of generalizability as it excluded people who are not active on SNS at the selected hours and selected days. Future research is recommended to address the data collection issue in order to provide more representative findings.

\section{REFERENCES}

Barry, C.T., Doucette, H., Loflin, D.C., Rivera-hudson, N., and Herrington, L.L. (2015) 'Let Me Take a Selfie ': Associations Between Self-Photography, Narcissism, and Self-Esteem. Psychology of Popular Media Culture ,20 (3), 106-116.

Fang Liu, Hong Cheng, \& Jianyao Li. (2009) "Consumer responses to sex appeal advertising: a cross-cultural study", International Marketing Review, 26 (4/5), 501 - 520 
Kim, H. and Ppacharissi, Z (2003). "Cross-cultural differences in online self-presentation: A content analysis of personal Korean and US home pages". Asian Journal of Communication, 13 (1), 100-119

Naumann, L.P., Vazire, S., Rentfrow, P.J., and Gosling, S.D. (2009) 'Personality Judgments Based on Physical Appearance.' Personality and social psychology bulletin 35 (12), 1661-1671

Qiu, L., Lu, J., Yang, S., Qu, W., and Zhu, T. (2015) 'What Does Your Selfie Say about You?' Computers in Human Behavior [online] 52, 443-449.

Sorokowski, P., Sorokowska, A., Oleszkiewicz, A., Frackowiak, T., Huk, A., and Pisanski, K. (2015) 'Selfie Posting Behaviors Are Associated with Narcissism among Men.’ Personality and Individual Differences [online] 85, 123-127.

Sorokowska, A., Oleszkiewicz, A., Frackowiak, T., and Pisanski, K (2016). "Selfies and personality: Who posts self-portrait photographs?". Personality and Individual Differences, 90, 119-123

Sun, T. and Wu, G. (2004) "Consumption patterns of Chinese urban and rural consumers", Journal of Consumer Marketing, 21 (4) 245 - 253

The Guardian (2015)" Brands Should Look Again at Using Selfies in Their Marketing Campaigns". Retrieved from http://www.theguardian.com/medianetwork/2015/may/05/brands-selfies-marketing-campaigns

Wall Street Journal (2014) "Smile, Marketing Firms are Mining Your Selfies". Retrieved from http://www.wsj.com/articles/smile-marketing-firms-are-mining-your-selfies1412882222

Wang, Y.-H. (2012) 'Taiwanese Girls ' Self -Portraiture on a Social Networking Site.' The London School of Economics and Political Science (July), 1-349

Weiser, E.B. (2015) '\#Me: Narcissism and Its Facets as Predictors of Selfie-Posting Frequency.' Personality and Individual Differences [online] 86, 477-481.

Zhao, X. and Belk, R. W. (2007)."Live From Shopping Malls: Blogs and Chinese Consumer Desire", Advances in Consumer Research, 34, 131-137. 